\title{
Pattern of antibiotics use, incidence and predictors of surgical site infections in a Tertiary Care Teaching Hospital
}

\author{
Ezaedin Halawi, Tamrat Assefa* and Sadikalmahdi Hussen
}

\begin{abstract}
Objective: Surgical site infections (SSIs) were the most common healthcare-associated infection mainly in developing countries. Inappropriate use of surgical antibiotic prophylaxis, in terms of antibiotic choice, timing, and duration, can lead to the selection of resistant microorganisms and high costs. The aim of this study was to investigate the pattern of antibiotic use, incidence and predictors of SSIs at Tikur Anbessa Specialized Hospital, Addis Ababa, Ethiopia.

Results: From 131 patients, 55.7\% were male study participants. Ninety (68.7\%) patients received preoperative prophylaxis. Ceftriaxone was the most 76 (84.5\%) prescribed agent for prophylaxis. Twenty-seven (20.6\%) patients developed surgical site infection. Previous surgery AOR $=3.22(95 \% \mathrm{Cl}[1.14-9.13])$ and alcohol use AOR $=7.04(95 \% \mathrm{Cl}$ $[2.56-23.12, p=0.000]$ ) were independent predictors of SSIs in multivariate logistic regression analysis.
\end{abstract}

Keywords: Pre and postoperative antimicrobial prophylaxis, Tikur Anbessa Specialized Hospital

\section{Introduction}

Surgical site infection (SSI) is an infection that happens within 30 days of operation or after 1 year if the implant is placed at or near the surgical incision [1]. It accounts for $17 \%$ of all healthcare associated infections and are the second most common hospital-acquired infections in study conducted in Ethiopia [2] and especially during post-operation period [3]. Globally, SSI rates have been found to be from 2.5 to $41.9 \%$. In Africa, SSIs were the leading infections in hospitals (pooled cumulative incidence of 5.6 per 100 surgical procedures), strikingly higher than proportions recorded in developed countries [1] as 13, 20.6, 10.9 and $10.9-75 \%$ rate of SSIs were reported in Nigeria [4], Cameron [5], Tanzania [6] and Ethiopia $[2,7]$ studies respectively.

The extent of microbial contamination at an incision site, host factors (such as age, nutritional status, lifestyle, comorbidities, immune-competency and coexisting infections), the length of the preoperative hospital period,

\footnotetext{
*Correspondence: tamrat.assefa@aau.edu.et Department of Pharmacology and Clinical Pharmacy, School of Pharmacy, Addis Ababa University College of Health Sciences, P.O.Box:1176, Addis Ababa, Ethiopia
}

preoperative procedures and the duration and performance of the operation contribute to increased risks of SSIs [8]. Patient characteristics possibly associated with increased risk of SSIs include coincident remote site infections or colonization, diabetes, cigarette smoking, systemic steroid use, obesity ( $>20 \%$ ideal body weight), extremes of age, poor nutritional status, and perioperative transfusion of certain blood products [9].

SSIs can have a devastating impact on the patient's course of treatment and is associated with increased treatment intensity, prolonged length of stay and higher costs [10]. A study in the United States of America suggested that programs that reduce the incidence of surgical site infections can substantially decrease morbidity and mortality and reduce the economic burden for patients and hospitals [11]. Despite improvements in operating room practices, instrument sterilization methods, better surgical technique and the best efforts of infection prevention strategies, SSIs remain a major cause of hospital-acquired infections and rates are increasing globally even in hospitals with most modern facilities and standard protocols of preoperative preparation and antibiotic prophylaxis [1].

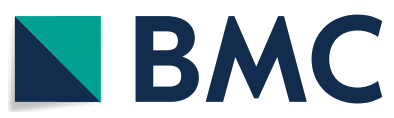

C The Author(s) 2018. This article is distributed under the terms of the Creative Commons Attribution 4.0 International License (http://creativecommons.org/licenses/by/4.0/), which permits unrestricted use, distribution, and reproduction in any medium, provided you give appropriate credit to the original author(s) and the source, provide a link to the Creative Commons license, and indicate if changes were made. The Creative Commons Public Domain Dedication waiver (http://creativecommons.org/ publicdomain/zero/1.0/) applies to the data made available in this article, unless otherwise stated. 
Another well-documented approach is to use pre and postoperative antimicrobial prophylaxis. From patients that received antimicrobial prophylaxis $30-90 \%$ are inappropriate; most antimicrobials are either given at the wrong time, wrong dosage and wrong strength which results in increased antibiotic usage, increased costs, prolonged hospitalization, super infection, antimicrobial resistance and reduction of surgical antimicrobial prophylaxis (SAP) used [12, 13].

Although the high incidence of SSI is suspected in Ethiopia, the magnitude of the problem is not known in TASH. It becomes therefore essential to determine the pattern of antibiotic use in surgical wards and occurrence and predictors of SSIs.

\section{Main text \\ Methods \\ Study setting}

The study was conducted in Tikur Anbessa Specialized Hospital (TASH) Addis Ababa, Ethiopia. TASH is one of the largest tertiary level, referral and teaching hospitals in the country, affiliated to Addis Ababa University. TASH has approximately 570 beds and out of this, 150 are allocated to surgical patients.

\section{Study design and period}

A prospective observational study was undertaken from April 1 to April 30, 2017. The source population was all inpatients admitted to the hospitals and undergone surgery, whereas the study population was all patients who had undergone operation and admitted to surgical ward during the study period.

\section{Inclusion and exclusion criteria}

All surgical patients who had operated during the study period and hospitalized up to 30 days were considered as eligible for the study. However, patients from other wards of the hospital (internal medicine, intensive care unit, emergency) and patients who died or left before third postoperative days and those not voluntary to participate were excluded from the study.

\section{Sample size and sampling technique}

Convenient sampling was used in as sampling technique in this study. Accordingly, all patients who had undergone surgical procedures are followed from admission until discharge, including any readmissions for infection. Accordingly, 131 patients were enrolled in our study.

\section{Data collection, management and quality assurance}

Socio-demographic characteristics of the patients, surgery-related information(site of surgery, duration of surgery, previous history of surgery, surgery type, hospital stay after surgery, wound class and occurrence of SSI after surgery within 30 days), antibiotic used (preoperative and postoperative antibiotic used, duration of antibiotics after surgery) were collected using data abstraction tool from patient's medical chart. The tool was developed from literatures and modified at it suits to study setting up and senior clinical pharmacist was consulted for its appropriateness. Patients were interviewed in case the information couldn't be obtained from their chart to make the data complete. Antimicrobial use evaluation was done according to Center for Disease Prevention and Control (CDC) criteria for using antimicrobials in surgical site infection (SSI) prevention and treatment [9]. In our set up, SSI diagnosed mainly by interpretation of clinical (sign and symptom manifestation) findings and also incorporating CDC definition and methodology. It is rare to use laboratory results (culture testing) in diagnosing SSI in the studied hospital. Incidence and risk factors for SSI, including those for specific procedures were calculated from data collected on daily base. Before the actual data was collected, a pretest of the data collection instrument was done to ensure the appropriateness of questionnaire and necessary modifications were made.

\section{Data entry and analysis}

Data was entered into and analyzed by SPSS version 20 . Logistic regression analysis was used to identify predictors of SSI. In all cases, p-value less than 0.05 are taken as statistically significant. Variables which have a significant association at $\mathrm{p}$-value $<0.25$ in the bivariate logistic regression analysis were candidates for multivariate logistic regression analysis to identify predictors of SSIs.

\section{Ethical considerations}

Ethical clearance was obtained from the ethics review committee of School of Pharmacy, College of Health Sciences, Addis Ababa University. Additionally written consent was taken from each participant before participating in the study.

\section{Results}

\section{Socio-demographic characteristics}

During the study period, a total of 158 patients underwent surgery in selected wards of the hospital. From the total, 27 patients were excluded by exclusion criteria (refused to provide consent or death or discharged too early after surgery) and finally, 131 patients were considered for analysis. The age of the patients ranged from 2 to 86 years with a mean of $41.15 \pm 18.29$ years. Twenty-two $(16.8 \%)$ and $41(31.3 \%)$ patients were smokers and alcohol drinkers respectively (Table 1 ). 
Table 1 Socio-demographic and clinical characteristics of patients at surgical wards of TASH $(\mathrm{N}=131)$

\begin{tabular}{|c|c|}
\hline Socio-demographic and clinical characteristics & $\mathrm{N}(\%)$ \\
\hline \multicolumn{2}{|l|}{ Gender } \\
\hline Female & $58(44.3)$ \\
\hline Male & $73(55.7)$ \\
\hline \multicolumn{2}{|l|}{ Age in years } \\
\hline$<30$ & $39(29.8)$ \\
\hline $30-50$ & $40(30.5)$ \\
\hline$>50$ & $52(39.7)$ \\
\hline \multicolumn{2}{|l|}{ Residence } \\
\hline Urban & $71(54.2)$ \\
\hline Rural & $60(45.8)$ \\
\hline \multicolumn{2}{|l|}{ Cigarette smoking } \\
\hline No & $109(83.2)$ \\
\hline Yes & $22(16.8)$ \\
\hline \multicolumn{2}{|l|}{ Alcohol intake } \\
\hline No & $90(68.7)$ \\
\hline Yes & $41(31.3)$ \\
\hline \multicolumn{2}{|l|}{ Preoperative blood transfusion } \\
\hline No & $101(77.1)$ \\
\hline Yes & $30(22.9)$ \\
\hline \multicolumn{2}{|l|}{ Systemic steroid use } \\
\hline No & $115(87.8)$ \\
\hline Yes & $16(12.2)$ \\
\hline \multicolumn{2}{|l|}{ Preoperative hospital stay (days) } \\
\hline$>7$ & $62(47.3)$ \\
\hline$\leq 7$ & $69(52.7)$ \\
\hline \multicolumn{2}{|l|}{ Co-morbidities } \\
\hline Cardiovascular disease & $20(15.3)$ \\
\hline Hypertension & $9(6.9)$ \\
\hline Diabetes mellitus & $2(1.5)$ \\
\hline HIV/AIDS & $5(3.8)$ \\
\hline Infection ${ }^{\mathrm{a}}$ & $8(6.1)$ \\
\hline Multiple co-morbidities & $7(5.3)$ \\
\hline Others $^{b}$ & $6(4.6)$ \\
\hline \multicolumn{2}{|l|}{ Wound class } \\
\hline Clean & $43(32.8)$ \\
\hline Clean contaminated & $64(48.9)$ \\
\hline Contaminated & $16(12.2)$ \\
\hline Dirty & $8(6.1)$ \\
\hline \multicolumn{2}{|l|}{ Surgery type } \\
\hline Emergency & $25(19.1)$ \\
\hline Elective & $106(80.9)$ \\
\hline \multicolumn{2}{|l|}{ Previous surgery } \\
\hline No & $98(74.8)$ \\
\hline Yes & $33(25.2)$ \\
\hline
\end{tabular}

Infection ${ }^{\mathrm{a}}$ infections other than SSIs. Others ${ }^{\mathrm{b}}$ include cancer, psychotic disorders, asthma, and epilepsy
Clinical characteristics and co-morbidities of the patients Nearly half of patients (47.3\%) stayed in hospital for more than 7 days before surgery was conducted. Fifty-seven (43.5\%) of the study participants had various types of comorbidities beside their surgery indications. Six (4.6\%) of them had more than co-morbidities (Table 1). About half of patients (48.9\%) who underwent operation had clean contaminated wounds at the time of surgery and the mean duration of operation was $2.21 \pm 1.53 \mathrm{~h}$. One hundred six (80.9\%) of the operations were elective surgery. One-fourth of patients had a history of previous procedure (Table 1).

\section{Practice and appropriateness of surgical antimicrobial prophylaxis}

Among 131 patients, more than two-third of (68.7\%) patients received preoperative antimicrobial prophylaxis. Out of the 43 and 64 patients who had a clean and clean contaminated wound, 15 (34.9\%) and 58 (90.6\%) patients received pre-operative antimicrobial prophylaxis respectively. From all patients that took preoperative antimicrobial prophylaxis eighty $(88.9 \%)$ patients received antimicrobial prophylaxis for greater than $24 \mathrm{~h}$ after surgery. The majority of patients received ceftriaxone 76 (84.5\%). The most commonly prescribed regimen among the combination regimens was ceftriaxone plus metronidazole 12 (13.3\%) (Table 2).

\section{Incidence of surgical site infections}

Among a total of 131 patients who underwent surgical procedures, SSI was developed in 27 (20.6\%) patients before discharge. Among the detected SSIs, 23 (85.2\%) and $4(14.8 \%)$ were superficial and deep infections respectively.

\section{Factors associated with surgical site infections}

Bivariate logistic regression model showed seven variables were associated with the occurrence of SSIs at $\mathrm{p}<0.25$. Alcohol $(\mathrm{p}=0.000)$, cigarette smoking $(\mathrm{p}=0.05)$, preoperative blood transfusion $(\mathrm{p}=0.05)$, contaminated $(p=0.17)$ and clean wound $(p=0.12)$, previous surgery $(p=0.01)$, and duration of surgery $(p=0.20)$ were candidate variables for multivariate analysis. The remaining factors were not associated with SSIs in studied participants (see Additional file 1).

\section{Predictors of surgical site infections}

Upon further analysis using multivariate analysis to evaluate whether these variables are independent predictors of SSIs, alcohol use and previous surgery were found to be independently associated with development of SSIs 
Table 2 Practice and appropriateness of surgical antimicrobial prophylaxis in surgery patients in TASH $(\mathrm{N}=131)$

\begin{tabular}{lc}
\hline Practice of antimicrobial prophylaxis(AMP) & N (\%) \\
\hline $\begin{array}{l}\text { Preoperative AMP provision } \\
\text { Yes }\end{array}$ & $90(68.7)$ \\
No & $41(31.3)$ \\
Preoperative provided antibiotics & \\
Ceftriaxone & $76(84.5)$ \\
Ceftriaxone and metronidazole & $12(13.3)$ \\
Ampicillin & $2(2.2)$ \\
Time of administration of preoperative AMP (h) & \\
$\leq 1$ & $34(37.8)$ \\
$>1$ & $56(62.2)$ \\
Duration of postoperative AMP (h) & \\
$\leq 24$ & $10(11.1)$ \\
$>24$ & $80(88.9)$ \\
Indication of AMP & \\
Indicated and administered & $73(91.25 \%)$ \\
Not indicated and not administered & $34(66.7 \%)$ \\
Indicated but not administered & $7(8.75 \%)$ \\
Not indicated but administered & $17(33.3 \%)$ \\
\hline
\end{tabular}

$(\mathrm{AOR}=7.70, \mathrm{p}=0.000),(\mathrm{AOR}=3.22, \mathrm{p}=0.028)$. However, other socio-demographic and clinical characteristics were not independently predictors of SSIs (Table 3 ).

\section{Discussion}

In this study, majority of patients who underwent surgical procedures received antimicrobial prophylaxis which is in line with another study [12]. However, proper AMP practice in this setup was not parallel with recommendations of the clinical practice guideline for antimicrobial prophylaxis in surgery $[14,15]$.

In this study, none of the patients received cefazolin even if it is recommended by guideline [14] in the prevention of most surgery related infections. The most commonly prescribed drug for AMP was ceftriaxone, followed by metronidazole, and it is comparable to study done in Brazil [16]. For surgical prophylaxis, it is important to select an antimicrobial with narrowest antibacterial spectrum to reduce the emergence of resistance and as for covering the most likely contaminating microorganisms for that type of surgery [14]. In all patients that received antimicrobial prophylaxis selection of antimicrobials were not consistent with the recommendations of the guidelines which may be due to the absence of their own guideline, the assumption of ceftriaxone

Table 3 Predictors of SSI development in surgery patients in TASH $(N=131)$

\begin{tabular}{|c|c|c|c|c|c|}
\hline \multirow[t]{2}{*}{ Variables } & \multicolumn{2}{|c|}{ Surgical site infection } & \multirow[t]{2}{*}{ COR $(95 \% \mathrm{Cl})$} & \multirow[t]{2}{*}{ AOR $(95 \% \mathrm{Cl})$} & \multirow[t]{2}{*}{$p$ value } \\
\hline & $\begin{array}{l}\text { Yes N (\%) } \\
27(20.6)\end{array}$ & 104 (79.4\%) & & & \\
\hline \multicolumn{6}{|c|}{ Preoperative blood transfusion } \\
\hline Yes & $10(33.3 \%)$ & $20(66.7 \%)$ & $2.47(0.98-6.21)$ & $1.34(0.45-4.02)$ & 0.602 \\
\hline No & $17(16.8 \%)$ & $84(83.2 \%)$ & & 1 & \\
\hline \multicolumn{6}{|l|}{ Cigarette smoking } \\
\hline Yes & $8(36.4 \%)$ & $14(63.6 \%)$ & $2.71(0.1-7.36)$ & $0.80(0.23-2.80)$ & 0.725 \\
\hline No & $19(17.4 \%)$ & $90(82.6 \%)$ & & 1 & \\
\hline \multicolumn{6}{|l|}{ Alcohol } \\
\hline Yes & $18(43.9 \%)$ & $23(56.1 \%)$ & $7.04(2.78-17.75)$ & $7.70(2.56-23.13)$ & 0.000 \\
\hline No & $14(14.74 \%$ & $81(85.26 \%)$ & & 1 & \\
\hline \multicolumn{6}{|l|}{ Wound class } \\
\hline Clean & $6(13.95 \%)$ & $37(86.05 \%)$ & $0.27(0.05-1.44)$ & $0.53(0.07-4.08)$ & 0.543 \\
\hline Clean contaminated & $16(25 \%)$ & $48(75 \%)$ & $0.56(0.12-2.59)$ & $1.04(0.16-6.57)$ & 0.966 \\
\hline Contaminated & $2(12.5 \%)$ & $14(97.5 \%)$ & $0.24(0.03-1.87)$ & $0.67(0.06-7.24)$ & 0.745 \\
\hline Dirty & $3(37.5 \%)$ & $5(62.5 \%)$ & & 1 & \\
\hline \multicolumn{6}{|l|}{ Previous surgery } \\
\hline Yes & $12(36.4 \%)$ & $21(63.6 \%)$ & $3.16(1.29-7.76)$ & $3.22(1.14-9.13)$ & 0.028 \\
\hline No & $15(15.3 \%)$ & 83 (84.7\%) & & 1 & \\
\hline \multicolumn{6}{|l|}{ Duration of surgery (h) } \\
\hline$>1$ & $19(24.1 \%)$ & 60 (75.9\%) & $1.81(0.73-4.51)$ & $2.16(0.72-6.48)$ & 0.169 \\
\hline$\leq 1$ & $8(15.4 \%)$ & $44(84.6 \%)$ & & 1 & \\
\hline
\end{tabular}


similar with cefazolin or unavailability of first generation cephalosporins.

Administration of AMP should be within $1 \mathrm{~h}$ prior to incision to achieve adequate protection [17]. In our study, only $37.8 \%$ of patients received preoperative antibiotics within $1 \mathrm{~h}$ prior to incision which is in agreement with Brazilian study [16]. However, AMP administration time is not recorded in 17 (18.9\%) patients may be due to work overload on attending nurses, the absence of separate sheet for recording time of administration and lack of awareness to record AMP administration time which is consistent with other studies [12].

Results from other study showed that duration of AMP was longer than $24 \mathrm{~h}$ in $30-90 \%$ of cases after surgery [18] and similarly this was observed in nearly $90 \%$ of our study participants. In general, single-dose prophylaxis or prophylaxis ending within $24 \mathrm{~h}$ after operation is recommended by guidelines [14]. Prolonged postoperative dosing of antibiotics does not provide additional benefits and is associated with increased risk of adverse events and induction of antimicrobial resistance $[14,15]$.

In most part of the world depending on the set up of their hospitals and their degree of adherence to aseptic techniques, the SSI rate has varied from a low of $2.5 \%$ to a high of 41.9\% [19-22]. The incidence rate of SSIs found in the present study was $20.6 \%$. It was higher than previous findings from developing country hospital 14.8\% [23] and from USA 7.2\% [24]. However, SSIs rate was similar to the study done in India $20.09 \%$ [25], and Nigeria 20.3\% [26] and Ethiopia 19.1\% [1]. But, it was more than three times lower when compared with the study conducted in Ethiopia 75\% [7]. The elevated SSI rates can be explained by the using clinical evidence than laboratory in the studied set up to detect SSI and limited ventilation in the operating theatre, as well as limited application of infection control measures.

In this study, alcohol use and having previous surgery was significant predictors of postoperative SSIs. The present study showed that patients with drinking alcohol were $7.70 \times$ more likely to develop SSIs compared with patients who do not drink alcohol with $A O R=7.04$ (95\% CI $[2.56-23.12, \mathrm{p}=0.000])$, and another study reported similar association [3]. Patients who had history of previous surgery were 3.16 times more likely to develop SSIs compared with those who hadn't previous surgery with $\mathrm{AOR}=3.22$ (95\% CI [1.14-9.13]), which was in agreement with another study [27]. Higher incidence of SSI in patients with previous surgery may be due to exposure to long operation time, difficult surgery, high class wounds and using the same incision site with the previous one.

Some studies have examined the use of the ASA score as a predictor of SSI risk [20, 28]. The ASA score approximates 'global' patient health at the time of the operation and is a reliable predictor of the risk of SSI [29]. This may be because these procedures were mainly performed on relatively normal physical activity before admission, which may limit the utility of the ASA score as a discriminator of risk. According to this study emergent surgeries $(24 \%)$ had higher rates of SSI than elective procedures $(19.8 \%)$. This is because, as emergency operations should be higher risk because of suboptimal preoperative preparation and because they are more likely to be dirty.

\section{Limitations}

We used smaller sample size and shorter study period which might have an impact on some of the results reported. Other factors have been known to influence the risk of SSIs, such as operation characteristics and nutritional status, antiseptic usage, and sterilization techniques and quality of operation theatre was not studied in this study.

\section{Additional file}

Additional file 1. Factors associated with SSIs occurrence among surgical patients in TASH $(\mathrm{N}=131)$. It is additional material which describes bivariate logistic regression model showing seven variables were associated with the occurrence of SSIs at $p<0.25$. Alcohol $(p=0.000)$, cigarette smoking $(p=0.05)$, preoperative blood transfusion $(p=0.05)$, contaminated $(p=0.17)$ and clean wound $(p=0.12)$, previous surgery $(p=0.01)$, and duration of surgery $(p=0.20)$ were candidate variables for multivariate analysis. The remaining factors were not associated with SSIs development in studied participants.

\section{Abbreviations}

AMP: antimicrobial prophylaxis; AOR: adjusted odds ratio; SAP: antimicrobial prophylaxis; SSI: surgical site infection; TASH: Tikur Anbessa Specialized Hospital.

\section{Authors' contributions}

SH conceived the study idea. EH developed the study design, conducted the study and analyzed data and it was enriched and approved by TA and SH. SH and TA did critical revisions of the manuscript for its important intellectual content. All authors read and approved the final manuscript.

\section{Acknowledgements}

We would like to express our gratitude to Tikur Anbessa Specialized Hospital who allowed us to conduct this study. We owe our deepest gratitude acknowledgment to data collectors and study participants.

\section{Competing interests}

The authors declare that they have no competing interests.

\section{Availability of data and materials}

The datasets used and/or analyzed during the current study are available from the corresponding author on reasonable request.

\section{Consent for publication}

Not applicable.

\section{Ethics approval and consent to participate}

Ethical clearance was obtained from the ethics review committee of School of Pharmacy, College of Health Sciences Addis Ababa University. Additionally written consent was taken from each participant before participating in 
the study. During the consent process, they were provided with information regarding the purpose of the study, why and how they were selected to be involved in the study and what will be expected from them.

\section{Funding}

We haven't received funding for this research work.

\section{Publisher's Note}

Springer Nature remains neutral with regard to jurisdictional claims in published maps and institutional affiliations.

Received: 6 June 2018 Accepted: 24 July 2018

Published online: 31 July 2018

\section{References}

1. Laloto TL, Gemeda DH, Abdella SH. Incidence and predictors of surgical site infection in Ethiopia: prospective cohort. BMC Infect Dis. 2017;17:1-9.

2. Mulu W, Kibru G, Beyene G, Demtie M. Postoperative infections and antimicrobial resistance pattern of bacteria isolates among patients admitted at felege Hiwot Refferal Hospital, Bahirdar, Ethiopia. Ethiop J Health Sci. 2012;22:7-18.

3. Hedrick TL, Sawyer RG, Friel CM, Stukenborg GJ. Method for estimating the risk of surgical site infection in patients with abdominal colorectal procedures. Dis Colon Rectum. 2013;56:627-37.

4. Amoran OE, Sogebi AO, Fatugase OM. Rates and risk factors associated with surgical site infections in a tertiary care center in South-Western Nigeria. Int J Trop Dis Heal. 2013;3:25-36.

5. Ngowe MN, Toure A, Mouafo FT, Chichom A, Tchounzou R, Ako-Egbe L, et al. Prevalence and risk factors associated with post operative infections in the Limbe Regional Hospital of Cameroon. Open Surg. 2014;8:1-8.

6. Mpogoro FJ, Mshana SE, Mirambo MM, Kidenya BR, Gumodoka B, Imirzalioglu C. Incidence and predictors of surgical site infections following caesarean sections at Bugando Medical Centre, Mwanza, Tanzania. Antimicrob Resist Infect Control. 2014;3:1-10.

7. Mengesha RE, Kasa BG, Saravanan M, Berhe DF, Wasihun AG. Aerobic bacteria in post surgical wound infections and pattern of their antimicrobial susceptibility in Ayder Teaching and Referral. BMC Res Notes. 2014;7:1-6.

8. Cooper RA. Surgical site infections: epidemiology and microbiological aspects in trauma and orthopaedic surgery. Int Wound J. 2013;10:3-8.

9. Mangram AJ, Horan TC, Silver Pearson ML, Jarvis WR, Guideline for Prevention of Surgical Site Infection. Centers for disease control and prevention (CDC) Hospital Infection Control Practices Advisory Committee. Am J Infect Control. 1999;1999(27):97-132.

10. De Lissovoy G, Fraeman K, Hutchins V, et al. Surgical site infection: incidence and impact on hospital utilization and treatment costs. Am J Infect Control. 2009;35:387-97.

11. Kirkland KB, Briggs JP, Trivette SL, et al. The impact of surgicsl site infection in the 1990s: attributable mortality, excess length os hospitalization, and extra costs. Infect Control Hosp Epidemiol. 1999;20:725-30.
12. Argaw NA, Shumbash KZ, Asfaw AA. Assessment of surgical antimicrobial prophylaxis in orthopaedics and traumatology surgical Unit of a Tertiary Care Teaching Hospital in Addis Ababa. BMC Res Notes. 2017;10:6-13.

13. Ciofi M, Alegiani SS, Raschetti R, Arace P, Giusti A, Spiazzi R, et al. Surgical antibiotic prophylaxis in children: adherence to indication, choice of agent, timing, and duration. Eur J Clin Pharmacol. 2015;71:483-8.

14. Bratzler DW, Dellinger EP, Olsen KM, Perl TM, Auwaerter PG, Bolon MK, et al. Clinical practice guidelines for antimicrobial prophylaxis in surgery. Am J Heal Pharm. 2013:70:195-283.

15. Scottish Intercollegiate Guidelines Network. Antibiotic prophylaxis in surgery. 2014. http://www.sign.ac.uk. Accessed 15 June 2018.

16. Rana DA, Malhotra SD, Patel VJ. Inappropriate surgical chemoprophylaxis and surgical site infection rate at a tertiary care teaching hospital. Braz J Infect Dis. 2013;17:48-53.

17. Thomas MF. Guidelines for Antimicrobial Prophylaxis in Surgery. Infect Dis ClinPract. 2013;21:185-6.

18. Elbur Al, Ma Y, Sayed A, Elsayed A, Abdel-Rahman EM. Prophylactic antibiotics and wound infection. J Clin Diagn Res. 2013;7:2747-51.

19. Demisew A, Tefera B, Fitsum A. Surgical site infection rate and risk factors among obstetric cases of Jimma University Specialized Hospital, Southwest Ethiopia. Ethiop J Health Sci. 2011;21:99-100.

20. Jasim HH, Sulaiman SAS, Khan AH, Dawood TO, Abdulameer HA, Usha $\mathrm{R}$. Incidence and risk factors of surgical site infection among patients undergoing cesarean section. Clin Med Insights. 2017;9:1-7.

21. Gonçalves da Silva QC, Barbosa MB. Risk factors for surgical site infection in cardiac surgery. Acta Paul Enferm. 2012;25:89-95.

22. Linda T. Infection prevention Guidelines for healthcare facilities with limited resources. 5th ed. Berlin: Springer; 2003.

23. Taye M. Wound infection in Tikur Anbessa hospital, surgical department. Ethiop Med J. 2005;43:167-74.

24. Garey KW, Dao T, Chen H, Amrutkar P, Kumar N, Reiter AM, et al. Timing of vancomycin prophylaxis for cardiac surgery patients and the risk of surgical site infections. J Antimicrob Chemother. 2006:58:645-50.

25. Mahesh CB, Shivakumar S, Suresh BSCS. A prospective study of surgical site infections in a teaching hospital. J Clin Diagn Res. 2010;4:3114-9.

26. Nwankwo EO, Ibeh INEO. Incidence and risk factors of surgical site infection in a tertiary health institution in Kano, Northwestern Nigeria. Int J Infect Control. 2012;8:8-13.

27. Haridas M, Malangoni MA. Predictive factors for surgical site infection in general surgery. Surgery. 2006;144:496-503.

28. Cheng K, Li J, Kong Q, Wang C, Ye N, Xia G. Risk factors for surgical site infection in a teaching hospital: a prospective study of 1138 patients. Patient Prefer Adher. 2015;9:1171-7.

29. Woodfield JC, Beshay NMY, Pettigrew RA, Plank LD, van Rij AM. American Society of anesthesiologists classification of physical status as a predictor of wound infection. ANZ J Surg. 2007;77:738-41.

Ready to submit your research? Choose BMC and benefit from

- fast, convenient online submission

- thorough peer review by experienced researchers in your field

- rapid publication on acceptance

- support for research data, including large and complex data types

- gold Open Access which fosters wider collaboration and increased citations

- maximum visibility for your research: over 100M website views per year

At BMC, research is always in progress.

Learn more biomedcentral.com/submissions 